\title{
O PROCESSO DE CRIAÇÃO DA ESCOLA TÉCNICA DE COMÉRCIO UNIÃO CAIXEIRAL A PARTIR DAS DEMANDAS SOCIOECONÔMICAS DO MUNICÍPIO DE MOSSORÓ, RN, ENTRE 1911 A 1937
}

\author{
T. S. BANDEIRA* e A. B. N. T. MENEZES \\ Universidade Federal do Rio Grande do Norte \\ taina_bandeira@hotmail.com*
}

Artigo submetido em abril/2016 e aceito em junho/2016

DOI: $10.15628 /$ rbept.2016.4458

\section{RESUMO}

A seguinte pesquisa tem por objetivo investigar o processo de criação da Escola Técnica de Comércio União Caixeiral através da relação entre a Sociedade União Caixeiral e o contexto socioeconômico do município de Mossoró, Rio Grande do Norte, no período de 1911 a 1937. Como abordagem utilizamos a dialética na concepção de Marx nos possibilitando perceber o diálogo existente entre o contexto socioeconômico da comunidade envolvente - Mossoró - e a criadora e mantenedora da escola - Sociedade União Caixeiral. Como esta pesquisa se insere no campo da História das Instituições Escolares, utilizamos Magalhães (2004) como referencial para entender como pesquisar nesse campo percebendo a Instituição Escolar na sua constituição e relação estabelecida com a comunidade em que está inserida. As análises nos levaram a compreender que a Escola Técnica de Comércio União Caixeiral foi pensada partindo das necessidades socioeconômicas do município de Mossoró uma vez que era o comércio a economia principal e o município era regido pela modernização que o crescimento econômico sinalizava. Porém, esse ensino técnico foi institucionalizado no município também determinado pelas dualidades que já existiam no ensino para o trabalho no contexto nacional caracterizando o cenário educacional mossoroense.

PALAVRAS-CHAVE: História das Instituições Escolares, Ensino Técnico, União Caixeiral.

\section{THE CREATING PROCESS OF THE TECHNICAL SCHOOL OF UNIÃO CAIXEIRAL TRADE FROM THE SOCIOECONOMIC DEMANDS OF MOSSORÓ CITY (RN), BETWEEN 1911 AND 1937}

\begin{abstract}
The following research aims to investigate the process of creation of the União Caixeiral Commercial Technical School through the relation between the União Caixeiral society and the socioeconomic context of Mossoro city, Rio Grande do Norte, in the period of 1911 to 1937 . We used Marx dialectic conception as approach, allowing us to perceive the existent dialog between the socioeconomic context of the involved community Mossoró - and the creator and sponsor of the school União Caixeiral Society. As the research inserts itself in the field of History of School Institutions, we used Magalhães (2004) as referential to understand this field,
\end{abstract}

realizing the School Institution in its constitution and established relationship with the community it is inserted. The analysis led us to understand the Technical School of União Caixeiral as a socioeconomic need of Mossoró, once the commerce was the main economy and the city was guided by the modernization that the economic expansion signaled. However, this technical teaching was institutionalized in the city for the duality that already existed in the instruction for work in the national context, characterizing the Mossoro educational scenario

KEYWORDS: History of School Institutions, Technical education, União Caixeiral. 


\section{APRESENTAÇÃO}

No Período Moderno o ensino para o trabalho começou a ganhar espaço dentro da sociedade capitalista que se consolidava, ganhando significação na ligação entre o trabalho e educação com base no modo de produção característica da sociedade capitalista que passou a determinar os valores, instituições, teorias e conhecimento (Frigotto, 1999). As profundas alterações nas relações de produção e capital oriundas com a Revolução Industrial trouxeram uma concepção de modelo educacional que teria o objetivo de suprir as exigências do mercado de produção. Nesse sentido, alguns ensinos antes transferidos informalmente, nesse momento, passaram a serem sistemáticos e formais com a institucionalização de escolas de agricultura, comércio, artes e ofícios (Manacorda, 1995). Com isso, o ensino direcionado à mão-de-obra possuía caráter emergencial atendendo a demanda econômica vigente.

No Brasil, o início do fornecimento do ensino direcionado ao trabalho teve cunho assistencialista. De forma sistemática e objetiva - pois antes desse momento eram práticas informais e espontâneas - podemos considerar que esse ensino passou a ser fornecido em 1809 com a criação do Colégio das Fábricas (Moura 2007), o qual foi criado sob a perspectiva assistencialista com o objetivo de atender parte da população que vivia em estado de mendicância, aos pobres e desvalidos (Cunha, 2000). Moura (2007) esclarece que

Essa lógica assistencialista com que surge a educação profissional é perfeitamente coerente com uma sociedade escravocrata originada de forma dependente da Coroa Portuguesa, que passou pelo domínio holandês e recebeu a influência de povos franceses, italianos, poloneses, africanos e indígenas, resultando em uma ampla diversidade cultural e de condições de vida ao longo da história - uma marca concreta nas condições sociais dos descendentes de cada um destes segmentos. (p.6)

A partir de 1920, o ensino profissional deixou de ter o caráter meramente assistencialista e passou a ser meio de controle do Estado, principalmente da classe dos trabalhadores urbanos que se mobilizavam e se organizavam formando palco de consideráveis lutas sociais (Manfredi, 2002). É nesse panorama social que a Escola Técnica de Comércio União Caixeiral passa a ganhar significação no plano das ideias e necessidades da Sociedade União Caixeiral pensando as demandas econômicas do município, isto é, uma escola de ensino comercial começou a ser pensada.

O ensino técnico encontrava campo fértil nas necessidades oriundas das mudanças socioeconômicas ${ }^{1}$. Com a década de 1930, ocorreram mudanças profundas com o processo de industrialização do Brasil que exigia um contingente de trabalhadores mais especializado para a indústria, comércio e prestação de serviços. Juntando a isso, o acontecimento da Segunda Guerra Mundial no qual os países desenvolvidos estavam concentrados na indústria bélica, permitiu o crescimento dos países emergentes e seus avanços industriais (Moura, 2007) (Cunha, 2000) (Manfredi, 2002).

\footnotetext{
${ }^{1}$ Cunha (2000) afirma que aconteceram na Primeira República profundas mudanças que se fortaleceram com o fim da escravatura, consolidação do projeto de imigração (trazendo consigo ideais anarquistas). Com isso, houve uma aceleração dos processos de industrialização, urbanização e modernização da tecnologia.
} 
Foi na década de 1930 que a Escola Técnica de Comércio União Caixeiral se constituiu em Instituição Escolar, e não fugiu ao seu momento histórico, pois foi pensada e criada com base no crescimento da economia comercial que se fortalecia no município de Mossoró. Tinha por objetivo inicial especializar os trabalhadores já inseridos no comércio, e atender os seus filhos com idade de usufruírem desse ensino, respondendo assim a demanda de especialidades e desenvolvimento dessa economia. Buscamos trabalhar nesse artigo o processo de criação da Escola Técnica de Comércio União Caixeiral. Essa escola foi criada pela Sociedade União Caixeiral em 1935 e funcionou até o ano 2000, no município de Mossoró, no estado do Rio Grande do Norte. Essa Instituição Escolar fornecia o ensino comercial e foi o maior grau até a criação da Faculdade de Contabilidade, em 1943, também pela Sociedade União Caixeiral.

A Sociedade União Caixeiral fez parte de um movimento protetor que ocorreu em diversas cidades do Brasil buscando ganhos para esse setor econômico. Como exemplo, podemos citar a Sociedade Fênix Caixeiral que funcionou em Fortaleza, Ceará, hoje extinta; em Parnaíba, Piauí, a União Caixeiral de Parnaíba que também foi criadora e mantenedora do Colégio Comercial União Caixeiral; a União Caixeiral de Piriri, também no Piauí, que manteve a Escola de Comércio Prof. Álvaro Ferreira; e a União Caixeiral Gabrielense, em São Gabriel no Rio Grande do Sul. Quando afirmamos ser um movimento protetor certificamos que eram grupos que se organizavam em prol de bens comuns aos comerciantes locais. Uma espécie de sindicato o qual buscava melhorias nas atividades e até regulamentação de seu funcionamento, dentro do município. Atuaram durante anos pensando no desenvolvimento e crescimento de suas atividades comerciais, sempre consoantes com as demandas estaduais e nacionais. Conseguiram se destacar dentro de seus municípios e, principalmente, as associações que forneceram outras atividades além do cunho econômico como práticas culturais e o ensino comercial.

A Sociedade União Caixeiral, que funcionou no município de Mossoró, Rio Grande do Norte, foi criada em vinte e sete de agosto de mil novecentos e onze. Os participantes do grupo que criou essa associação foram: Francisco Izódio de Souza, Alcides Galvão de Miranda, Afonso Freire, Felipe Guerra, Raimundo Nonato de Souza, Sebastião Fernandes Gurgel e Antônio Filgueira Mendes (Nonato, s/d). Foi criadora de duas instituições de ensino: a Escola Técnica de Comércio União Caixeiral, criada em 1936, que funcionava no prédio que hoje abriga a Biblioteca Municipal Ney Pontes Duarte, sendo a Sociedade União Caixeiral mantenedora até o fim do exercício dessa escola, em 2000; e o Curso Superior de Administração e Finanças que foi transformada posteriormente na Faculdade de Ciências Econômicas e incorporada à Universidade Estadual (Nonato, 1973).

Diante desse processo de constituição da Sociedade União Caixeiral em fornecedora de educação, temos por objetivo investigar o momento do pensar e criar a Escola Técnica de Comércio União Caixeiral através da relação entre a Sociedade União Caixeiral e o contexto socioeconômico mossoroense, Rio Grande do Norte, entre o ano de 1911 a 1937. Entendemos por momento de pensar o processo em quem a Sociedade União Caixeiral começa a entender a importância de um maior nível de especialização dos trabalhadores do comércio o que acarretou nas práticas informais e, posteriormente, na institucionalização do ensino comercial em Mossoró. Esse processo inicial de percepção das necessidades citadas anteriormente, foram constatadas com a dinâmica da Sociedade União Caixeiral, na sua dialética com a comunidade que a envolvia. Quanto ao recorte temporal, 1911 se justifica por ter sido o ano de criação da Sociedade União Caixeiral e, consequentemente, o ano que iniciou a relação com os contextos de Mossoró; 1937 é o ano em 
que o prédio sede foi entregue e a escola, já foi institucionalizada, passa a funcionar de forma plena.

Magalhães (2004) afirma que uma Instituição Escolar tem sua formação e exercício determinados pela comunidade envolvente com quem dialoga constantemente e, portanto, também caracterizando essa sociedade. Especificamente no caso da Escola Técnica de Comércio União Caixeiral, os contextos do município de Mossoró determinaram a criação dessa Instituição Escolar, mas analisar a relação com todos eles despenderia período longo para obter respostas. Junto a esse fato, pudemos perceber em nossos estudos que foram as demandas econômicas que atuaram diretamente na criação da escola, se justificando assim, a análise da dialética entre o contexto socioeconômico e o processo de criação.

Nonato (1973) afirmou que a Sociedade União Caixeiral já pensava o ensino comercial logo após a sua criação com o exercício de aulas comerciais ainda não formalizadas e constituídas como em uma Instituição Escolar. Nossas análises se iniciaram desde a criação da Sociedade União Caixeiral quando iniciou a relação do pensar o ensino comercial com o contexto socioeconômico. Com isso foi possível problematizar essa relação, indagando em que medida o contexto socioeconômico foi determinante no processo de pensar e criar a Escola Técnica de Comércio União Caixeiral pela Sociedade União Caixeiral. Por ser essa a discussão levantada, nosso trabalho pertence a área da História da Educação, especificamente ao campo da História das Instituições Escolares. Apesar das pesquisas da área da História da Educação terem seu crescimento nas décadas de 1960 e 1970 - com o acentuado aumento dos programas de pós-graduações em educação - foi em 1990 que as pesquisas sobre a História das Instituições Escolares tiveram maior ênfase. O estudo desse campo, com base em Magalhães (2004), nos possibilitou entender que a história de uma escola

É uma história material, social, cultural, biográfica, reflexiva, que procura uma objetividade e sentido de inquérito, na contextualização, descrição, narrativa, compreendendo e explicando o presente-passado por referência ao destino dos sujeitos e à evolução da realidade. (Magalhães, 2004, p. 71)

Como suporte para pensar a relação entre a criação da escola e as determinações do contexto socioeconômico decidimos por trabalhar sob a abordagem dialética na concepção de Marx (Konder, s/d). Assim conseguimos perceber "a conexão íntima entre a forma pela qual a sociedade produz sua existência material e a escola que cria" (Buffa; Nosella, 2005, p.363). com isso, conseguimos entender a forma com que a comunidade pensa as suas necessidades e demandas e a forma concreta de ação para supri-las. No caso de uma Instituição Escolar, ela é pensada e criada partindo das necessidades de uma sociedade, oriundas de práticas informais e constituídas em instituição (Saviani, 2007). Como referencial teórico metodológico utilizamos Magalhães (2004) para compreendermos como pesquisar no campo das História das Instituições Escolares inseridos na dialética com a comunidade envolvente. Ainda pensando a Instituição Escolar inserida nessa relação comunidade - escola, utilizamos Buffa e Nosella (2005) que pensa a escola na dialética na concepção de Marx. Sob essa abordagem e com esse aparato teórico metodológico, segurança de afirmar que os planos econômico, social, cultural, educacional, político e outros - considerados a totalidade dessa escola - foram determinante para que tenha existido o pensar e o institucionalizar essa escola. Portanto, a abordagem dialética se faz necessária. 


\section{CONTEXTO SOCIOECONÔMICO}

Mossoró é um município que se constituiu a partir da pecuária nas margens do rio ApodiMossoró. Em 1857, apesar de ter tido um desenvolvimento lento, exportava couros, algodão, sal, carne seca, cera de carnaúba e resina de angico (Souza, 1979) através do porto de Areia Branca, considerado porto de Mossoró até 1950 (Felipe, 2001). Esse crescimento nas exportações e importações configura o município na sua região:

A geografia da cidade passa a ser marcada pela sua localização espacial, pela sua transição entre a economia do litoral e a economia do sertão, condições privilegiadas naquele contexto histórico, que viabilizam a cidade a participar da divisão internacional do trabalho, como centro sertanejo de exportação e importação de mercadorias. (Felipe, 2001, p.35)

Esse desenvolvimento atraiu comerciantes estrangeiros de diferentes nacionalidades como o suíço (Henri Burly), e o italiano (Teles Filizola) que juntaram-se aos comerciantes locais, como Tertuliano Fernandes, formando a classe comercial que caracterizaria o município de Mossoró. Entre 1883 a 1885 o porto de Mossoró recebeu "113 embarcações nacionais e 143 estrangeiras" (Lira apud Felipe, 2001, p.40). Apesar de pontos negativos como a seca do ano de 1877, os comerciantes mossoroense se beneficiavam com a grande quantidade de possível mão-de-obra com a chegada dos retirantes em um contingente de " 25.000 pessoas que a tudo expunham-se para receber um litro de farinha" (Guerra; Guerra apud, Felipe, 2001, p.43). A força braçal dos retirantes também foi utilizada na construção de prédios públicos como a Cadeia Municipal, trazendo um sopro de modernização e melhoramento à cidade. O fato é que o comércio se firmou como base econômica do município e assim permaneceu até os dias atuais seguindo as mudanças sociais. Mossoró se tornou importante dentro de sua região caracterizada por sua construção socioeconômica.

Quando falamos sobre as mudanças sociais, afirmamos que a base econômica se reconfigurou na medida que a sociedade se deparou com situações pontuais. A seca de 1877 pode ser apontada como forte razão para essa modificação da dinâmica econômica mossoroense. De um lado, o favorecimento dos comerciantes locais que eram pagos pelo governo para o fornecimento de alimentos dos retirantes (e assim tiveram renda para manter seus pontos comerciais), e os salineiros por terem sido os que mais exploraram os retirantes como mão-deobra abundante; Por outro lado, enfraqueceu o comércio de importação e exportação de mercadorias prejudicando os mercadores estrangeiros que fecharam suas empresas e saíram da cidade. Unida ao problema da seca, a dificuldade do deslocamento das mercadorias, devido ao trem ainda não circular por Mossoró, também ajudou nessa reconfiguração da economia mossoroense. Felipe (2001) esclarece essa nova dinâmica da econômica do município:

[...]mantém o seu comércio em evolução, agora tocado, especificamente, pelos capitais locais que, segundo recenseamento (1890-1900) publicado no Boletim Bibliográfico de no 39, constava das seguintes firmas: Romualdo Lopes Galvão (algodão e peles), Borges Irmãos (exportadora), Souza Nogueira e Cia (importação e exportação), Oliveira Irmão (importação e exportação), Aderaldo Zózimo e Filhos (exportadora), Viúva Reis, Horácio Cunha e Cia., Manoel Tavares Cavalcante e Cia., Bento Oliveira e Cia., Leite e Irmãos, Benício e Mota, Cirilo e Nogueira, e, ainda, os comerciantes: Antonio Silva de Medeiros, Manoel Cirilo dos Santos, Silvio 
Policiano de Miranda, Manso Valente Cavalcanti, Frederico Sabóia, Manuel Lucas da Mota, João Valério de Medeiros e Rocha Limeira (Brito, 1982). Esse comércio se recompõe também com a chegada de outros sujeitos: é o caso do farmacêutico Jerônimo Rosado, que 27 de abril de 1890, requeria licença para estabelecer sua farmácia e drogaria na rua do Graf. (p.48-49)

Mossoró passa, nesse momento, a ser um "escoadouro natural das matérias primas. 0 comércio local supre os pedidos do sertão inteiro. Tem-de-tudo, com abundância, variedade, modernice" (Cascudo, 1967, p.48). Com isso, os comerciantes, envoltos ao fortalecimento da economia, formam uma elite local de gostos refinados. No início do Período Republicano, essa elite local acaba se tornando exemplos de civilizadores a serem seguidos. Homens que faziam de um município pequeno um espaço de desenvolvimento social (Felipe, 2001). Essa "elite agráriocomercial" (Felipe, 2001, p. 50) tentava copiar um comportamento cosmopolita, consumiam produtos oriundos da França e Inglaterra, estimulavam as apresentações "[...] das companhias teatrais nacionais e estrangeiras, o gosto pela leitura que induzia a formação de bibliotecas com livros adquiridos na Europa e no Rio de Janeiro" (ibid., p. 50). Some-se a isso

A criação de instituições culturais, bibliotecas, clubes literários, semanários, jornais, grupos de teatro amadores e sala de projeção cinematográfica [que] sinalizavam os novos hábitos da modernidade local que se completavam com a criação dos colégios para instrução secundária, no caso, o Colégio Sete de Setembro, criado em 1900 e o Colégio Diocesano Santa Luzia, em 1901. (ibid. p. 51)

Em um espaço não tão glamoroso e cosmopolita estavam os comerciantes menores, pequenos fornecedores de matérias primas e os donos das bodegas ${ }^{2}$. Esses pequenos comerciantes tinham seus pontos em lugares mais afastados das ruas com maior movimentação comercial, exatamente entre a praça, onde se localiza hoje a Catedral de Santa Luzia, e o próprio Mercado Público da Cidade (construído entre os anos de 1875 e 1877 e reformado em 1907 e 1931). Esses pontos de comerciantes menos favorecidos se localizavam em locais que Raimundo Nonato (1957) considera parte de baixa da cidade. A verdade é que a elite cosmopolita era uma pequena parcela da sociedade e que possuía o controle econômico, social e político da cidade. Mas esse poder foi construído em detrimento da qualidade de vida da maioria da sociedade mossoroense que sucumbia na precariedade, sofrendo com período de seca e a falta sistemática de água e assolada por doenças que eram "reinantes na transição de uma estação a outra" (Santos, 1990, p.7).

Mesmo com essa divisão de classe acentuada (e que não difere do restante do país) não podemos descartar o fato de que o comércio se desenvolveu de tal forma que se tornou a base econômica do município. Foi nessa configuração socioeconômica que a Sociedade União Caixeiral foi criada, em 1911. Essa foi a primeira entidade de classe mossoroense que reuniu comerciantes locais para pensar ações de benefício comum a sua profissão, tendo como primeiro presidente Manuel Marques acrescido da figura de Francisco Izódio de Souza que fizeram crescer a associação dentro do município. Muitas associações se multiplicaram no município, de acordo com Nonato (1973) surgiram grupos que reuniram artistas, homens das mais diversas atividades como artesãos,

\footnotetext{
${ }^{2}$ Termo muito comum na sociedade mossoroense em tempos passados e trazido por Raimundo Nonato em sua obra Memórias de um Retirante (1957).
} 
trabalhadores rurais e operários das salinas e das prensas de algodão. Ainda afirma que foram "precursoras do movimento de sindicalização das classes, cuja marcha, durante anos, nem sempre foi a mais pacífica" (p. 28).

De acordo com seu primeiro estatuto, a Sociedade União Caixeiral tinha por objetivo a defesa dos direitos da classe comercial atendendo aos interesses dos empregados. Com isso, compreendemos que, incialmente, essa associação tinha como membros representantes dos comerciantes menos abastecidos. Outro fator que nos leva a crer nessa afirmação é o fato de ter como um dos principais representantes Francisco Izódio - figura de suma importância no grupo que era de origem humilde e descendente de escravos (Nonato, 1957) e só ganhou notoriedade posterior a criação da Sociedade União Caixeiral, o que nos leva a entender que essa associação foi criada com características trabalhistas. Uma das primeiras conquistas da Sociedade foi a determinação de que as casas comerciais teriam que funcionar até as 18 horas ao invés de se prolongarem até 20, 21 horas. Porém, o sentimento de desenvolvimento que predominava no país que caracterizou a elite mossoroense também reestruturou a Sociedade União Caixeiral quanto aos seus objetivos saindo do estritamente econômico e se expandido para outros espaços como o político e, principalmente quando tentamos entender o processo de criação da escola, o educacional. Mudou também o posicionamento dos atuantes dentro do município tornando-se figuras de renome que passaram a exercer funções em outras entidades e em cargos políticos.

Nas primeiras décadas do Período Republicano3, o Brasil vivia uma busca pela modernização dos seus aparelhos sociais. A acentuação das práticas higienistas (oriundas ainda no Império), a construção dos Grupos Escolares e as remodelações na estrutura das capitais brasileiras (período da Belle Époque) foram ações características desse sentimento de desenvolvimento. Já na década de 1920 o Brasil começa a ter um caráter industrial o que também modificou a formato assistencialista que possuía o ensino técnico, passando a ser meio de ensino instrumental da classe trabalhadora na busca de contingente mais especializado. No município de Mossoró, esse sentimento de modernização sai do espaço do consumo restrito à elite (produtos importados para usufruto próprio) e alcança a infraestrutura do município - que apesar de ser oriunda das necessidades sociais mais voltadas aos interesses dessa mesma elite econômica foram benefícios de usufruto também de uma parcela maior da sociedade. Como símbolo desse desenvolvimento local, podemos citar a inauguração do Cine-teatro Almeida Castro, em 1908; a criação das escolas secundárias (citadas anteriormente acrescida do Colégio Sagrado Coração de Maria, em 1912); o Tiro de Guerra, em 1911; e os dois principais símbolos desse desenvolvimento urbano: a finalização da linha férrea com a chegada do primeiro comboio, em 1915, e o recebimento da luz elétrica licenciada a empresa "Força, Luz e Melhoramento de Mossoró", em 1916, além da reforma de amplificação do Mercado Público, em 1930, este, símbolo maior do crescimento comercial (Nonato, 1965) (Cascudo, 2010).

Somam-se a esses acontecimentos, a fixação de empresas fornecedoras de produtos que também caracterizavam essa modernização, como a empresa de transporte de automóvel de Tertuliano Fernandes \& Cia e empresas de beneficiamento de matérias-primas "é o caso do algodão com o descaroçamento (para a feitura do óleo comestível), prensagem e confecção de fios

\footnotetext{
${ }^{3}$ Cunha (2000) afirma que aconteceram na Primeira República profundas mudanças que se fortaleceram com o fim da escravatura, consolidação do projeto de imigração (trazendo consigo ideais anarquistas). Com isso, houve uma aceleração dos processos de industrialização, urbanização e modernização da tecnologia.
} 
e tecidos para sacaria" (Felipe, 2001, p.61). Ainda de acordo com Felipe (2001), o contexto econômico do município de Mossoró, a partir da década de 1920 até, aproximadamente, 1954, foi marcado por essas iniciativas de desenvolvimento e modernização do município. "A especialização industrial de Mossoró é determinada pelos processos de industrialização do Centro-Sul do Brasil, particularmente de São Paulo, que passa a requisitar matéria-prima para as suas indústrias" (ibid, p. 63).

Apesar de ter beneficiado uma parcela considerável da sociedade mossoroense, esses símbolos de desenvolvimento se tornaram meios de fixar um ideário de heroísmo em relação a elite comercial, principalmente na figura da família Rosado. Atualmente, o comércio e seus representantes são considerados a razão do crescimento de Mossoró, a base da modernização que o município teria por diante. "O passado heroico dos 'Civilizadores de Mossoró' é o grande espelho, que os Rosados transformaram em imaginário político e usaram essas imagens para criar outras, pois um lugar de tantos heróis e de tantas 'virtudes' se assemelha a um grande país - 'país de Mossoró'”' (Felipe, 2001, p. 64).

\section{UMA INSTITUIÇÃO ESCOLAR É PENSADA}

A Sociedade União Caixeiral foi criada em 27 de agosto de 1911, quando Mossoró vivia a plena busca pela modernização e desenvolvimento comercial. Junto a outras entidades, como a 2 de Julho, essa associação foi fruto do seu momento, consequência do caráter social que a economia modelava. Com objetivos em comum, comerciantes e trabalhadores desse espaço se uniram para pensar melhorias. Porém, como instituição de seu tempo, logo se direcionou aos desejos de fazer parte da parcela da população que se constituía nos construtores de desenvolvimento. Aliás, não foi particular da Sociedade União Caixeiral querer ser mais que objetivavam inicialmente, as entidades que em Mossoró existiram, estavam sempre envolvidas em movimentos que pensavam a existência de grupos de artes, construções de bibliotecas, participações em eventos religiosos: "É de se pôr em relevo os serviços que essas entidades prestavam ao ensino, mantendo escolas, bibliotecas, órgãos de publicidade, além do incentivo que davam às práticas do civismo e do desenvolvimento dos esportes" (Nonato, 1973, p. 28).

Na década de 1920, em pleno desenvolvimento do comércio e a busca por um processo inicial de industrialização, a elite socioeconômica também pensava a educação como suporte para o desenvolvimento, tanto o ensino direcionado aos seus filhos como o direcionado aos seus funcionários. Essa atenção para o âmbito educacional se espelhava no que acontecia no Brasil, principalmente na atual Região Sudeste, por exemplo o desenvolvimento dos Grupos Escolares e Escolas Normais. O cenário educacional de Mossoró, com o advento da República, consolidou com a criação das escolas secundárias, além do Grupo 30 de Setembro (1909) e a Escola Normal (1922). É interessante ressaltarmos que apesar da Escola Normal ser, teoricamente, uma Instituição Escolar de natureza profissional para a formação de professores, em algumas cidades ela foi direcionava ao ensino dos filhos da elite local. Como exemplo, podemos citar a Escola Normal de São Carlos, Estado de São Paulo, que atendeu a esse público específico oferecendo um ensino além do esperado para uma educação profissional (Buffa; Nosella, 1996). A Escola Normal de Mossoró também teve um direcionamento ao ensino intelectual dos filhos da elite, Nonato (1957) em suas narrativas memorialísticas, expõe um fato que bem exemplifica esse direcionamento: “[...] pois vinha sabendo que, dias antes, o próprio diretor, acompanhado do Dr. Eufrásio de Oliveira, visitara 
as casas das famílias importantes onde havia jovens em idade escolar, e tinham pedido que os mesmos concorressem ao exame" (p. 145).

Quanto ao ensino dos trabalhadores e seus filhos, foram direcionadas práticas informais de ensino comercial, isto é, ainda na década de 1920 (15 anos antes da Escola Técnica de Comércio União Caixeiral iniciar seu funcionamento) a Sociedade União Caixeiral já pensava e executava o exercício de um ensino que tentasse atender as demandas da economia que se tornara base do município. O ensino técnico no país ganha uma nova configuração, deixando de ser assistencialista e passando a ser um meio de especializar a mão-de-obra necessária para as novas demandas econômicas (Bandeira, 2015). Educação extremamente instrumental, apenas voltada ao trabalho sem nenhuma iniciativa cultural, intelectual ou formação humana não diferente do contexto do ensino profissional do país, o quê nas primeiras práticas eram direcionados a parcela da população que vivia em estado de mendicância (Moura, 2007), nesse momento, passa a ser direcionado aos trabalhadores como forma de treinar para os novos desafios econômicos, a mão-de-obra tinha que ser especializada. Esse cenário emergencial acentuou mais ainda as dicotomias existentes entre o ensino fornecido aos filhos dos trabalhadores e aos filhos da elite no cenário educacional mossoroense que não se diferenciava das dualidades já existente no contexto educacional nacional. Quando comparamos o ensino técnico ao ensino básico acentua a "vertente mais instrumental [que] é permitida aos filhos das classes populares, enquanto a educação básica de caráter mais propedêutico é dirigida à formação das elites" (Moura, 2007, p.5).

Kuenzer (1997) afirma que a dualidade existia desde o curso primário. Enquanto o percurso do ensino básico (primário e ginasial) que era direcionado aos filhos da elite fornecia preparação e maiores oportunidades para adentrar no ensino superior a posteriore, aos filhos das classes mais baixas eram destinados ensinos que tinham caráter de finalidade específica como os cursos Normal e Comercial. Mesmo com todas as modificações após a década de 1930 quando houve uma atenção maior direcionada para a educação, partindo de todo o processo de crescimento da industrialização do país e o ensino profissional sob outra visão - de especialização para o trabalho - as dualidades ainda permaneceram (Cunha 2000). Na Constituição Federal de 1937 é perceptível essa dualidade quando decreta que

Art 129 - A infância e à juventude, a que faltarem os recursos necessários à educação em instituições particulares, é dever da Nação, dos Estados e dos Municípios assegurar, pela fundação de instituições públicas de ensino em todos os seus graus, a possibilidade de receber uma educação adequada às suas faculdades, aptidões e tendências vocacionais.

O ensino pré-vocacional profissional destinado às classes menos favorecidas é em matéria de educação o primeiro dever de Estado. Cumpre-lhe dar execução a esse dever, fundando institutos de ensino profissional e subsidiando os de iniciativa dos Estados, dos Municípios e dos indivíduos ou associações particulares e profissionais. (Art. 129)

Pensando no cenário educacional mossoroense, as dicotomias também eram características determinantes. Por um lado, o ensino direcionado aos filhos da elite já era institucionalizado, o ensino direcionado à mão-de-obra permaneceu por período acentuado informalmente. Isso nos permitiu perceber o descaso das instâncias políticas com esse ensino e o quanto estava vinculado à demanda socioeconômica. Além disso, podemos observar um fato 
decorrente desse ensino, que é o seu fornecimento ter origem privada. As práticas de ensino comercial, tanto quando ainda eram informais como as oferecidas posteriormente já institucionalizadas e fornecidas na Escola Técnica de Comércio União Caixeiral, em Mossoró, tivera como criador e mantenedor o grupo privado constituído na Sociedade União Caixeiral permanecendo nessa situação até o fim do exercício da escola, e mesmo recebendo incentivos da instância estadual, em determinado momento, ainda era de cunho privado.

A forma como o ensino comercial foi se fixando em Mossoró - práticas informais e depois a sua institucionalização - caracteriza a própria natureza de uma Instituição. Uma escola pensada dentro da dinâmica de uma determinada comunidade, que ao perceber necessidades especificas exercem práticas informais como forma de suprir essas demandas. É nessa dialética com a comunidade e seus variados contextos que essas práticas informais vão respondendo às demandas, tornando-se essenciais àquela sociedade naquele momento, constituindo-se em Instituição (Saviani, 2007). Partindo desse entendimento, conseguimos perceber a institucionalização do ensino comercial no município de Mossoró, a medida que as práticas informais desse ensino, exercidas pela Sociedade União Caixeiral, foram suprindo as necessidades socioeconômicas constituindo assim a economia e o tão buscado desenvolvimento social, essenciais até a constituição em escola.

Quando compreendemos e explicamos a história de uma Instituição, a integramos no quadro mais amplo do sistema social que a pensou e a criou, nos contextos e nas circunstâncias históricas, de forma interativa e que implica na evolução da comunidade, públicos e zonas de influências em que estão inseridos. Pesquisar a história da Escola Técnica de Comércio União Caixeiral é perceber o fornecimento do ensino técnico (o ensino comercial, especificamente), entender as conjunturas socioeconômicas do município de Mossoró compreendendo que o percurso histórico dessa escola está imbricado na sociedade mossoroense. Isso acontece pela própria dinâmica de formação de uma Instituição. Uma Instituição não surge repentinamente, ela é constituída a partir de práticas informais, práticas cotidianas que passam a ser pensadas como necessárias e vão sendo sistematizadas. Contudo, não são todas as práticas exercidas que se constituem em Instituições, apenas as que, em seu processo de sistematização, conseguem resolver problemas surgidos dentro da comunidade e se tornam essenciais. Com as permanências e rupturas da existência dessa comunidade, essas práticas se reinventam e continuam a suprir as demandas, modificando também os contextos que a determinam, na constante relação dialética até que esse diálogo não funcione mais e a Instituição deixe de existir. Portanto, essas práticas são criadas a partir de problemas reais, concretos e não apenas existentes no plano do pensamento. Nesse sentido, as instituições possuem caráter de solução, sendo - no processo de institucionalização - planejadas, sistematizadas e concretizadas (Saviani, 2007). Essas práticas informais e espontâneas, no ato de percepção da necessidade de sistematizar e institucionalizar, deixam de ser práticas primárias e passam a serem consideradas secundárias e intencionais. Com isso,

[...]podemos dizer que, de modo geral, o processo de criação de instituições coincide com o processo de institucionalização de atividades que antes eram exercidas de forma não institucionalizada, assistemática, informal, espontânea. A instituição corresponde, portanto, a uma atividade primária que se exerce de modo difuso e intencional. (Saviani, 2007, p. 5) 
A Escola Técnica de Comércio União Caixeiral seguiu a natureza de uma Instituição Escolar com práticas informais de ensino comercial oferecidas pela Sociedade União Caixeiral em um primeiro momento na década de 1920. Quando estava sob a direção de Alcides Dias e Thiers Rocha, a Escola Técnica de Comércio União Caixeiral foi instalada em Mossoró, tendo como seu primeiro diretor o próprio Thiers Rocha. Para a sua organização, foi solicitado a ajuda da Escola de Comércio de Natal que enviou instruções indispensáveis para a organização do processo de pedido de verificação prévia, iniciando com o curso propedêutico. O prédio sede (e que faz parte do cenário do município até hoje) só foi construído em 1937. Também nesse ano a escola foi inspecionada pelo Inspetor Federal Abdon Pimentel que fora recomendado pelo professor Tércio Rosado autorizando, assim, o funcionamento da escola sob o regime da Inspeção do Ministério da Educação. Porém, a portaria que autorizou foi do dia 13 de agosto de 1940 - Portaria Ministerial no 166 - publicado no Diário Oficial da União de 30 de agosto do mesmo ano. Constituiu-se, de forma concreta, uma solução paras demandas socioeconômicas mossoroenses, a escola viera para atender "estudantes pobres que precisavam de procurar durante o dia os meios com que estudar a noite" (Nonato, s/d, p. 5). Essa Instituição Escolar possuiu caráter de especializar a mão-de-obra e, também, de suprir a educação de famílias menos favorecidas economicamente, apesar de ser uma escola privada concedia bolsas aos alunos mais carentes. O processo de criação da Escola Técnica de Comércio União Caixeiral reafirmou a configuração que o próprio ensino técnico ganhara no cenário educacional do país.

\section{CONSIDERAÇÕES FINAIS}

Analisando o processo de criação da Escola Técnica de Comércio União Caixeiral temos condição de afirmar que ela foi pensada e criada partindo de demandas socioeconômicas. Porém, não ignoramos o fato de que uma Instituição é construtora de sua identidade, e como tal, tem condições de responder a dialética que estabelece com a comunidade envolvente. Devido a isso, a escola também possuiu configuração própria, reafirmando ou não determinações provenientes dos contextos que dialogou. Quando observamos a escola objeto de nosso estudo, percebemos que ela ia de encontro, em alguns pontos, com o que se fazia parte da configuração do ensino técnico no Brasil. Um exemplo foi o prédio em que era fornecido o ensino, construção majestosa que se destacava no município, típico dos prédios das escolas que forneciam ensino aos filhos da elite e incomum aos espaços que forneciam ensino técnico, isto é, a Escola Técnica de Comércio União Caixeiral, quanto construtora de sua identidade, pode responder também contrária as determinações de sua comunidade envolvente, respostas essas que podem ser percebidas na análise sob a abordagem da dialética. Por outro lado reafirmava as dicotomias quando "a escola, na verdade, só possuía, em ótimas condições, o prédio [...] não havia nada além das salas de aula e da ideia de fazê-la sobreviver" (Nonato, s/d, p. 31).

A Escola Técnica de Comércio União Caixeiral foi uma resposta à busca de uma Mossoró cosmopolita, uma forma de difundir valores e preceitos do momento socioeconômico que se estabelecia. Instruir essa mão-de-obra e aos seus filhos também facilitou incutir um ideário da elite construtora de modernização e salvadora de um município que necessitava dela. Dessa maneira, famílias, como a dos Rosados, se estabeleceram, até os dias atuais, fomentando um poder socioeconômico, cultural e político em Mossoró. 


\section{REFERÊNCIAS}

1. BRASIL. Constituição dos Estados Unidos do Brasil (de 10 de Novembro de 1937) Disponível em https://www.planalto.gov.br/ccivil_03/constituição/constitui\%C3\%A7ao37.htm. Acesso $13 / 11 / 2015$.

$2 . \quad$ Conselho Nacional de Educação. Parecer CNE/CEB no 16/99, de 05 de outubro de 1999. Dispõe sobre as Diretrizes Curriculares Nacionais para a Educação Profissional de Nível Técnico. Disponível em http://portal.mec.gov.br/cne/index.php?option=content\&task=view\& id=147\&ltemid=206\#1999B. Acesso 13/11/2015.

3. BUFFA, Ester. História e filosofia das instituições escolares. In: ARAÚJO, José Carlos Souza; GATTI JUNIOR, Décio (org). Novos temas em história da educação brasileira: instituições escolares e educação na imprensa. Campinas: Autores Associados, 2002. p. 25-38.

4. ‥ A questão das fontes de investigação em História da Educação. Campo Grande: Série-Estudos, n.12, jul.dez.2001, p.79-86.

5. _ Os estudos sobre instituições escolares: organização do espaço propostas pedagógicas. In: NASCIMENTO, Maria Isabel Moura; SANDANO, Wilson; LOMBARDI, José Claudinei; SAVIANI, Dermeval (orgs). Instituições Escolares no Brasil: conceito e reconstrução histórica. Campinas, SP: Autores Associados, 2007.p. 151-164.

6. _ _ Práticas e fontes de pesquisa em história da educação. In: GATTI Jr., Décio; FILHO, Geraldo Inácio (orgs.). História da Educação em perspectiva: ensino, pesquisa, produção e novas investigações. São Paulo: Autores Associados; Minas Gerais: EDUFU, 2005. p. 105-132.

7. BUFFA, Ester; NOSELLA, Paolo. As pesquisas sobre instituições escolares: o método dialético marxista de investigação. ECCOS, São Paulo. v. 7, n. 2, p. 351-368, jul./dez. 2005.

8. CASCUDO, Luís da Câmara. Notas e documentos para a história de Mossoró. Mossoró: Fundação Vingt-um Rosado, 2010. 5 ed. Coleção Mossoroense, série C, v. 1571.

9. FELIPE, José Lacerda Alves. A (re)invenção do lugar: os Rosados e o "País de Mossoró". João Pessoa: Grafset, 2001.

10. GATTI Jr., Décio. A história das instituições educacionais: inovações paradigmáticas e temáticas. In: ARAÚJO, José Carlos Souza; GATTI JUNIOR, Décio (org). Novos temas em história da educação brasileira: instituições escolares e educação na imprensa. Campinas: Autores Associados, 2002. p. 3-24.

11. GATTI Jr, Décio; PESSANHA, Eurize Caldas. História da Educação, Instituições e Cultura Escolar. In: GATTI Jr., Décio; FILHO, Geraldo Inácio (orgs.). História da Educação em perspectiva: ensino, pesquisa, produção e novas investigações. São Paulo: Autores Associados; Minas Gerais: EDUFU, 2005. p. 71-90.

12. LOMBARDI, José Claudinei; SAVIANI, Dermeval (orgs). Instituições Escolares no Brasil: conceito e reconstrução histórica. Campinas, SP: Autores Associados, 2007.p. 3-27.

13. LOMBARDI, José Claudinei. Reflexões sobre educação e ensino na obra de Marx e Engels. 2010. Tese (Doutorado) - Programa de Pós-Graduação em Educação - Departamento de Filosofia e História da Educação. Universidade Estadual de Campinas. 377p.

14. KUENZER, Acácia Zeneida. Ensino Médio e Profissional: as políticas do Estado neoliberal. São Paulo: Cortez, 1997. 
15. MAGALHÃES, Justino Pereira de. A história das instituições educacionais em perspectiva. In: GATTI Jr., Décio; FILHO, Geraldo Inácio (orgs.). História da Educação em perspectiva: ensino, pesquisa, produção e novas investigações. São Paulo: Autores Associados; Minas Gerais: EDUFU, 2005. p. 91-103.

16. MAgALHÃES, Justino Pereira de. Tecendo Nexos: história das instituições educativas. Bragança Paulista: Editora Universitária São Francisco, 2004.

17. MAGALHÃES, Justino Pereira de. Contributo para a história das instituições educativas entre memória e o arquivo. Braga-Portugal: Universidade do Minho, 1996.

18. MANACORDA, Mario Alighiero. Marx e a Pedagogia Moderna. São Paulo/Campinas: Cortez/Autores Associados, 1991.

19. MARX, Karl. Contribuição à crítica da economia política. São Paulo: Editora Expressão Popular. 2.ed. 2008.

20. _. O capital, Crítica da economia política. Rio de Janeiro: Civilização Brasileira, 1974.

21. . Para a Crítica da economia política. Do capital. 0 rendimento e suas fontes. São Paulo: Nova Cultural, 1999. Col. Os Pensadores.

22. MARX, Karl; Engels, Friedrich. A ideologia alemã. Trad. Luis Cláudio de Castro e Costa. São Paulo: Martins Fontes, 1998.

23. MARX, K.; ENGELS, F. A Ideologia Alemã: crítica da filosofia alemã mais recente na pessoa dos seus representantes Feuerbach, B. Bauer e Stirnes, e do socialismo alemão na dos seus diferentes profetas. Volume I e II. Lisboa: Editorial Presença; Brasil: Livraria Martins Fontes. [s.d.].

24. MARX, Karl. O Método Dialético. In:__; ENGELS, Friedrich. Ludwig Feurerbach e o Fim da Filosofia Clássica Alemã e outros Textos Filosóficos. Lisboa: Editorial Estampa, 1975.

25. MOURA, Dante Henrique. Educação Básica e Educação Profissional e Tecnológica: dualidade histórica e perspectivas de integração. Holos. Ano 23, v.2. 2007.

26. NONATO, Raimundo. Memória de duas épocas. Rio de Janeiro: Edição do Centro NorteRiograndense, 1967.

27. . Memórias de um retirante. Rio de Janeiro: Irmãos Pongetti, 1957.

28. Somando os dias do tempo: memórias. Rio de Janeiro: Pongetti, 1973.

29. ___ Ruas, caminhos da saudade. Mossoró, 1973. Coleção Mossoroense. v. 23.

30. Al_ Alcides Fernandes: Um pioneiro do ensino comercial. Coleção Mossoroense. Série B - Folhetos.

31. A escola de outro tempo. Rio de Janeiro: Pongetti, 1968. Coleção Mossoroense, série V, v. 22.

32. Zona do pôr do sol: tempo e os homens da província. Rio de Janeiro: Potenghi, 1964.

33. Terra e gente de Mossoró: conferência pronunciada em 30 de setembro de 1964. Mossoró, [s/d], 1965.

34. SANFELICE, José Luís. História das Instituições Escolares: desafios teóricos. 
35. Série-Estudos - Periódico do Mestrado em Educação da UCDB. Campo Grande-MS,n.25, p. 1117, jan./jun. 2008.

36. SANFELICE, José Luís. História das Instituições Escolares. In: NASCIMENTO, Maria Isabel Moura; SANDANO, Wilson; LOMBARDI, José Claudinei; SAVIANI, Dermeval (orgs). Instituições Escolares no Brasil: conceito e reconstrução histórica. Campinas, SP: Autores Associados, 2007.p. 75-94.

37. SAVIANI, Dermeval. Instituições Escolares no Brasil: conceito e reconstrução histórica. In: NASCIMENTO, Maria Isabel Moura; SANDANO, Wilson; LOMBARDI, José Claudinei; SAVIANI, Dermeval (orgs). Instituições Escolares no Brasil: conceito e reconstrução histórica. Campinas, SP: Autores Associados, 2007.p. 